\title{
Rapid Changes in the Genetic Composition of Stagonosporopsis tanaceti Population in Australian Pyrethrum Fields
}

\author{
Niloofar Vaghefi, Frank S. Hay, Peter K. Ades, Sarah J. Pethybridge, Rebecca Ford, and Paul W. J. Taylor
}

First, fifth, and sixth authors: Faculty of Veterinary and Agricultural Sciences, The University of Melbourne, Victoria, 3010, Australia; second author: Tasmanian Institute of Agriculture, University of Tasmania, Burnie, Tasmania, 7320, Australia; third author: Department of Forest and Ecosystem Science, The University of Melbourne, Victoria, 3010, Australia; and fourth author: Cornell University, Department of Plant Pathology and Plant-Microbe Biology, Geneva, NY 14456.

Accepted for publication 8 September 2014.

\begin{abstract}
Vaghefi, N., Hay, F. S., Ades, P. K., Pethybridge, S. J., Ford, R., and Taylor, P. W. J. 2015. Rapid changes in the genetic composition of Stagonosporopsis tanaceti population Australian pyrethrum fields. Phytopathology 105:358-369.

A novel set of microsatellite markers were developed and employed for geographical and temporal population analyses of Stagonosporopsis tanaceti, the cause of ray blight of pyrethrum in Australia. Genotyping of 407 isolates, using 13 markers, suggested an asexual mode of reproduction with significant linkage disequilibrium and high levels of clonality.

tanaceti was stable for a decade then changed rapidly in only 2 years. Bayesian clustering analyses and minimum spanning networks determined only two major clonal lineages in and prior to 2010. However, in 2012, a previously unobserved cluster of MLGs was detected, which significantly increased in frequency and displaced the historically dominant MLGs by 2013. This rapid change in the genetic composition of $S$. tanaceti could indicate a second introduction then a selective sweep, or strong selection pressures from recently introduced fungicides or pyrethrum varieties. These results may have serious implications for durability of management strategies for this disease.
\end{abstract} Low geographical differentiation and widespread distribution of a few multilocus genotypes (MLGs), in the absence of airborne ascospores, suggested the role of human-mediated movement of seed as a major means of long-distance pathogen dispersal. The genetic composition of $S$.
Additional keywords: microsatellite development, S. chrysanthemi, S. inoxydabilis, temporal population genetics.

MAT1-1-1 and MAT1-2-1, in a single genome. However, the reproductive mode of $S$. tanaceti is not completely understood but is hypothesized to primarily reproduce asexually, due to the absence of a teleomorph (24), and identification of only one matingtype gene (MAT1-1-1) in field populations (67). Population genetic studies using amplified fragment length polymorphism (AFLP) and random amplified polymorphic DNA (RAPD) also suggested little or no sexual recombination due to high linkage disequilibrium (52).

Ray blight was initially observed in Tasmanian pyrethrum fields in 1995 (53) and was considered minor until 1999, when epidemics resulted in severe crop losses. The origin of $S$. tanaceti in Australia and the reason for its sudden outbreak in the late 1990s is not known. Factors hypothesized as contributing to the increase in epidemic severity were recent changes in field establishment methods from vegetative propagation to seeding and/or changes in the aggressiveness of the pathogen population (47).

No pyrethrum varieties resistant to ray blight have yet been found, and disease management currently depends on the intensive use of fungicides $(42,49,50,51)$. Infected seed is believed to be the major source of $S$. tanaceti primary inoculum in pyrethrum fields $(41,44)$ and seeds are treated with fungicides before planting. Multiple autumn and winter fungicide applications are followed by prophylactic use of fungicides in spring, which is applied three times at 2 -week intervals. Fields may receive up to 11 applications of fungicides in the first 18 months before the first harvest for management of ray blight and multiple other fungal diseases $(42,47)$.

Reduced sensitivity of $S$. tanaceti (previously known as Phoma ligulicola var. inoxydabilis) to difenoconazole, which was previ-

http://dx.doi.org/10.1094/PHYTO-08-14-0212-R

(C) 2015 The American Phytopathological Society 
ously used to manage the disease in spring (25), suggests the pathogen population may be evolving resistance to at least some fungicides. The only population study of $S$. tanaceti analyzed samples collected prior to 2004 and reported high genotypic diversity but no evidence for sexual reproduction (52). Thus, little is known about the genetic structure of the current $S$. tanaceti population in Australia. Therefore, more recent populations of $S$. tanaceti should be studied to characterize the current genetic structure and diversity, and putative temporal changes in the population following continued selection on the population from fungicides. Moreover, efficiently breeding pyrethrum for resistance to ray blight requires a better understanding of the genetic diversity and evolutionary potential of the pathogen $(29,30)$.

This paper reports the development of microsatellite markers for $S$. tanaceti and their transferability to the two phylogenetically close species; $S$. chrysanthemi and $S$. inoxydabilis. The newly developed markers were further employed to quantify the amount and distribution of genetic diversity in the $S$. tanaceti population, and investigate possible changes in the genetic composition of the population over time. The objectives were therefore to (i) quantify diversity and determine whether the population consists of a wide range of genotypes or a few founder genotypes; (ii) test for genetic differentiation between populations sampled from different regions/fields/pyrethrum varieties; (iii) identify any changes in the genetic diversity and composition of $S$. tanaceti population since its discovery in the late 1990s; and (iv) test the occurrence of sexual reproduction in $S$. tanaceti populations in pyrethrum fields.

\section{MATERIALS AND METHODS}

Isolates and DNA extraction. $S$. tanaceti isolates $(n=407)$ were obtained from commercial pyrethrum fields along the Northern coast of Tasmania (Fig. 1). Isolations were conducted from leaf lesions as described by Pethybridge et al. (48). For long-term storage, $1-\mathrm{cm}^{2}$ mycelial plugs on potato dextrose agar were dried in a biohazard cabinet overnight and subsequently stored in sterile cryogenic tubes at $-80^{\circ} \mathrm{C}$. The samples belonged to four temporal populations. The term population herein will be used to refer to a group of isolates defined under certain geographical or temporal criteria (e.g., collected within a region or in the same year). The four temporal populations consisted of three populations collected in $2010(n=40), 2012(n=178)$, and 2013 ( $n=143)$, in addition to 46 isolates collected in and prior to 2004 (Fig. 1). The pre-2004 collection had been collected arbitrarily from 37 pyrethrum fields between 1998 and 2004 and was included to enable analysis of the $S$. tanaceti population close to its first report in 1995 (53). The 2010 isolates were randomly sampled from 21 pyrethrum fields located in nine regions. Sampling in 2012 was conducted in a two-tiered fashion that included intensive sampling from two fields at Table Cape (field 70042, $n=41$; and field 70047, $n=32$ ) combined with less intensive and more geographically diverse sampling from 10 fields in five other regions. The intensive sampling was done by collecting samples every $50 \mathrm{~cm}$ along $50 \mathrm{~m}$ transects, which were positioned $34 \mathrm{~m}$ apart from each other. For temporal analysis, the 2013 collection included intensive sampling from the same transects as in 2012 (field 70042, $n=45$; and field 70047, $n=50$ ) in Table Cape, and also a third field located $60 \mathrm{~km}$ away (field 49301 in Forthside, $n=48$ ). This resulted in at least 80 samples from each field; therefore, 45 to 50 samples representing spatially separated points on the transects were selected randomly for genotyping.

Isolates of $S$. chrysanthemi and $S$. inoxydabilis were obtained from international culture collections described in Table 1. For DNA extraction, single-spored isolates were grown in CzapekDox broth for 5 days in the dark at $125 \mathrm{rpm}$, and genomic DNA was extracted using the DNeasy Plant Mini Kit (Qiagen, Australia) according to the manufacturer's instructions.
Microsatellite discovery and primer design. We initially used PAL_FINDER (11) for microsatellite discovery in unassembled Illumina paired-end reads of S. tanaceti. However, of a total of 60 primer pairs tested, only a small fraction of the detected loci $(18 \%)$ was amplifiable after many rounds of optimization. Moreover, sequencing of the products showed that some did not contain a microsatellite region (data not shown). As an alternate approach, a previously assembled, partial genome of $S$. tanaceti with a total size of $40.8 \mathrm{Mbp}$ (67) was screened for SSR motifs using the software Tandem Repeat Finder (8). The search was conducted for all the di- to hexa-nucleotide repeat motifs with a minimum score of 50 and a matching point of 2 . A total of 204 $(9.5 \%)$ of the 2,156 scaffolds were found to contain the defined repeat motifs. Forty-four primer pairs for amplification of microsatellites were designed using the program Primer3 (58) with the parameters set as default except for a GC content of greater than $30 \%$, a maximum poly- $\mathrm{N}$ of 4 bases, and product sizes ranging from 100 to $450 \mathrm{bp}$ to maximize the potential for multiplexing. The sequences containing the SSR motifs were blasted against the nr database of the NCBI to make sure they did not belong to genic regions.

Cross-species transferability. The 44 primer pairs were tested for amplification of a single intense band in reference strains of S. tanaceti (CBS 131484), S. chrysanthemi (CBS 500.63), and S. inoxydabilis (CBS 425.90). Polymerase chain reaction (PCR) was performed in $12 \mu \mathrm{l}$ final volume containing $10 \mathrm{ng}$ of template DNA, Immolase PCR buffer (Bioline (Aust) Pty. Ltd., Alexandria, New South Wales, Australia), $1.5 \mathrm{mM} \mathrm{MgCl}_{2}, 0.5 \times$ Bovine serum albumin (BSA) (New England BioLabs Inc., Ipswich, MA), $0.2 \mathrm{mM}$ of each dNTPs (Bioline, (Aust) Pty. Ltd.), $0.3 \mathrm{U}$ of Immolase DNA polymerase (Bioline (Aust) Pty. Ltd.), and $0.1 \mu \mathrm{M}$ of each forward and reverse primer. Thermal cycling was performed on a thermocycler (Bio-Rad Laboratories Pty. Ltd., Gladesville, New South Wales, Australia) as follows: $15 \mathrm{~min}$ denaturation at $95^{\circ} \mathrm{C}$ followed by 35 cycles of $30 \mathrm{~s}$ at $95^{\circ} \mathrm{C}, 30 \mathrm{~s}$ at $60^{\circ} \mathrm{C}$ and $30 \mathrm{~s}$ at $72^{\circ} \mathrm{C}$, and a final extension step of $10 \mathrm{~min}$ at $72^{\circ} \mathrm{C}$. Products were visualized on $1.2 \%$ agarose gel. Primers that successfully resulted in a single amplicon of the expected size in any of the three species were selected for further polymorphism tests on the target species. The PCR products were subsequently sequenced in both directions at the Australian Genome Research Facility (AGRF), Melbourne, Victoria, Australia to confirm they represented the target repeat sequences.

Test for allelic variation and multiplex PCR optimization. To assess polymorphism, each primer was tested separately against 24 S. tanaceti isolates from the 2010 population as well as six $S$. chrysanthemi and three $S$. inoxydabilis isolates (Table 1). A modified 13-tailed priming protocol described by Schuelke (60) was used as follows: $12 \mu \mathrm{l}$ reaction mix consisted of $10 \mathrm{ng}$ of template DNA, Immolase PCR buffer (Bioline (Aust) Pty. Ltd.), $1.5 \mathrm{mM} \mathrm{MgCl} 2,1.5 \times \mathrm{BSA}$ (New England BioLabs Inc.), $0.2 \mathrm{mM}$ of each dNTPs (Bioline (Aust) Pty. Ltd), 0.3 U of Immolase DNA polymerase (Bioline (Aust) Pty. Ltd.), $0.06 \mu \mathrm{M}$ the universal FAM-labeled M13 (-21) primer (5'-TGTAAAACGACGGCCA GT-3'), $0.04 \mu \mathrm{M}$ of the M13-tagged forward primer, and $0.1 \mu \mathrm{M}$ of the sequence-specific reverse primer. Thermal cycling was performed on a thermocycler (Bio-Rad Laboratories Pty. Ltd.) with 15 min denaturation at $95^{\circ} \mathrm{C}$ followed by 32 cycles of $30 \mathrm{~s}$ at $95^{\circ} \mathrm{C}, 30 \mathrm{~s}$ at $60^{\circ} \mathrm{C}$ and $30 \mathrm{~s}$ at $72^{\circ} \mathrm{C}$, followed by eight cycles of $30 \mathrm{~s}$ at $95^{\circ} \mathrm{C}, 30 \mathrm{~s}$ at $53^{\circ} \mathrm{C}$ and $30 \mathrm{~s}$ at $72^{\circ} \mathrm{C}$ and a final extension step of $10 \mathrm{~min}$ at $72^{\circ} \mathrm{C}$. Capillary electrophoresis was conducted at AGRF on a 96-capillary ABI 3730 DNA analyzer using LIZ 500 size standard (Life Technologies Australia Pty. Ltd., Mulgrave, Victoria, Australia). Allele sizes were determined using the Genemapper v. 4.0 software (Life Technologies Australia Pty. Ltd.).

Those markers that were found to be polymorphic for $S$. tanaceti were subsequently combined into multiplex PCR mixes containing two to four primer pairs (Supplemental Table 1) using 
Multiplex Manager (19). Minimum distance between the loci was set to $30 \mathrm{bp}$ and a complementary threshold of 7 was allowed. Multiplex reactions were performed in $12 \mu \mathrm{l}$ volumes consisting of $10 \mathrm{ng}$ of template DNA, Immolase PCR buffer (Bioline (Aust) Pty. Ltd.), $1.5 \mathrm{mM} \mathrm{MgCl}$, $1.5 \times$ BSA (New England BioLabs Inc.), $0.2 \mathrm{mM}$ of each dNTPs (Bioline (Aust) Pty. Ltd.), $0.3 \mathrm{U}$ of Immolase DNA polymerase (Bioline (Aust) Pty. Ltd.), and the corresponding fluorescent-labeled M13 primer and locus-specific primers.

Genotyping. For the main genotyping, the 16 polymorphic loci were arranged into six multiplex PCR mixes labeled with FAM, PET, and NED fluorescent dyes, and were then pooled into three bins for capillary electrophoresis. S. tanaceti isolates showing null alleles were re-run to decrease the genotyping error. Moreover, genotyping was replicated for a subset of 80 samples, as well as isolates with rare alleles, to confirm reproducibility and quantify error rates. Mean error rate $\left(\mathrm{e}_{1}\right)$ was calculated for each locus (54), and loci with error rates of more than 0.04 were eliminated from the analyses. The Ewens-Watterson neutrality test (28) was conducted using 1,000 simulated samples in POPGENE v. 1.32 (71) to test selective neutrality of each of the microsatellite loci.

Genetic diversity indices. Basic indices of genetic variation were calculated for each population; defined by the year of collection, and subpopulations; defined by region, pyrethrum variety, and, where sample sizes allowed, pyrethrum field.

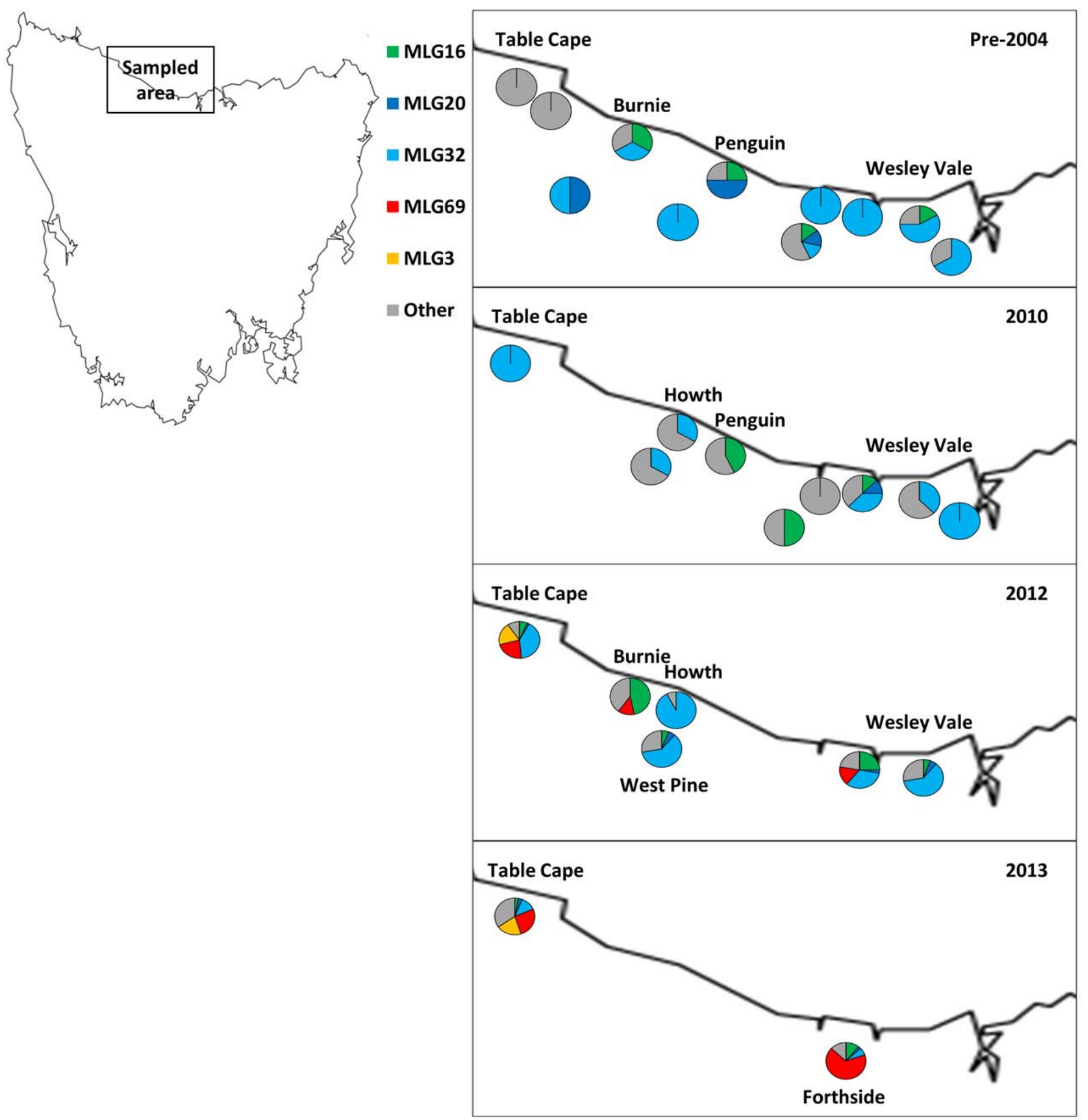

Fig. 1. Geographic location of the four Australian Stagonosporopsis tanaceti populations genotyped, showing the five most frequent multilocus genotypes (MLGs). 
Average allelic/gene diversity $\left(\mathrm{Nei}\right.$ 's $\mathrm{H}_{\mathrm{e}}$ ) was calculated in ARLEQUIN v. 3.5 (18). To enable comparison of allelic diversities among populations and subpopulations with different sample sizes, allelic richness $\left(\mathrm{R}_{\mathrm{a}}\right)$, defined as the mean number of alleles per locus, and private allelic richness $\left(\mathrm{P}_{\mathrm{a}}\right)$ were estimated using the rarefaction approach implemented in ADZE v. 1.0 (65).

Based on Arnaud-Haond et al.'s (3) description of the three nonredundant indices required to fully describe population diversity, GENCLONE (2) was used to estimate the genotypic richness $(\mathrm{R})$, evenness $\left(\mathrm{ED}^{*}\right)$, and the slope of the Pareto distribution $(\beta)$. Dorken and Eckert's (16) modification of genotypic richness (R) increases as the number of multilocus genotypes (MLGs) increase and ranges from 0 (in monoclonal populations) to 1 (absence of clonality). Evenness index (ED*) adapted from Simpson's complement index estimates the equability in the distribution of the sampling units and varies from zero (no evenness) to one (when all MLGs have equal abundance) (3). The slope of the Pareto distribution $(\beta)$ integrates the indices of richness and evenness to give a representation of heterogeneity. High $\beta$ values (steep slope) are indicative of high evenness with clonal lineages of approximately the same size, while lower $\beta$ values indicate very few large lineages and multiple small ones (3). Genotypic diversity ( $\left.\mathrm{D}^{*}\right)$ was also estimated using the program GENCLONE to provide the unbiased estimator of Simpson's complement index, defined as the probability that two randomly chosen individuals have different MLGs. Significance of the differences in genotypic diversities between subpopulations was tested in GenoDive (31) using 999 bootstrapped data sets sampling to match population sizes.

Temporal analysis of genetic diversity. For temporal analysis of gene diversity, homogeneity of gene frequencies across years was tested through construction of two way contingency tables and chi-square test in POPGENE (71). For temporal analysis of genotypic diversity, significance of the differences between populations was tested in GenoDive using 999 bootstrapped data sets. Also, pairwise comparison of genotypic composition in different years was done using 999 permutations in GenoDive. This is similar to testing for differences in allele frequencies, only in this case the alleles have been replaced by genotypes to test whether genotype frequencies differ between two populations.

Analysis of molecular variance (AMOVA) was conducted in ARLEQUIN v. 3.5 to determine the partitioning of genetic variation within regions in each year and among years, using Weir and Cockerham's (70) unbiased estimator of the fixation index $\left(\mathrm{F}_{\mathrm{ST}}\right)$. The significance of $\mathrm{F}_{\mathrm{ST}}$ was tested using 10,000 permutations.

MLG analyses. Isolates with the same combination of alleles were considered as clones or MLGs. Number of MLGs in each population, and the expected number of MLGs after rarefaction (eMLG) (20) was obtained using the R package Poppr $(26,57)$, which is specifically designed for analyzing clonal and partially clonal populations. Recurrent genotypes and their frequency across populations were also obtained using Poppr. In order to ascertain clonal identity of the identical MLGs, the probability of identical MLGs being the result of independent sexual repro- ductive events (rather than clonal reproduction) was estimated as $P_{\text {sex }}$ in GENCLONE.

Population structure and differentiation. AMOVA was conducted in ARLEQUIN to determine the partitioning of genetic variation within and across populations through Weir and Cockerham's (70) $\mathrm{F}_{\mathrm{ST}}$, and 10,000 permutations. For the pre-2004 collection and the 2010 population, comparison of subpopulations from different regions or host varieties was not meaningful due to small sample sizes. However, half of the 2010 isolates were collected from 3-year-old fields (planted in 2007) while the other half belonged to 1-year-old fields. Therefore, 1- and 3-year-old populations in 2010 were compared. The 2012 and 2013 isolates were grouped into different regions and fields, and into subpopulations according to pyrethrum varieties.

Minimum spanning networks for each population were constructed based on Bruvo's distance (9) using the R package Poppr on non-clone-corrected data sets. Bruvo's method uses a stepwise mutation model to calculate genetic distance of the individuals using microsatellite data. The networks were visualized using the package igraph (15).

To test for existence of an underlying structure in the species and infer the most likely number of populations in each year, two approaches were implemented. Since $S$. tanaceti is clonal and reproducing mainly asexually, it violates the assumptions of Hardy-Weinberg equilibrium and linkage equilibrium of loci in model-based clustering approaches such as STRUCTURE (55). Therefore, exploratory approaches that do not require assumptions of particular genetic models were adopted for detection of substructures in each year.

First, a distance-based dendrogram was constructed through unweighted pair group method with arithmetic mean (UPGMA) (59) using the Bruvo's distance in Poppr. Significance was assessed using 1,000 bootstrap replicates. Second, discriminant analysis of principal components (DAPC) (23) implemented in the R package ADEGENET (22) was used. The most likely number of clusters within the $S$. tanaceti populations was estimated based on the Bayesian information criterion (23).

Linkage disequilibrium analyses. The $\mathrm{R}$ package Poppr was used to test the random association of alleles (null hypothesis of panmixia) for each population by calculating the standardized index of association $\bar{r}_{d}(1)$, which is not dependent on the number of loci. A value of zero indicates lack of association of alleles (linkage equilibrium) which is expected in randomly mating populations. A value significantly different from zero is indicative of linkage between loci, which is expected to be high in clonal populations. As a second test of linkage disequilibrium, the ratio of $\mathrm{Vo} / \mathrm{Ve}$ was estimated in GenALEx v. 5 (38) and significant departure from one was tested using 999 permutations.

\section{RESULTS}

Microsatellite primer design and cross-species transferability. The search for SSR motifs in the partially assembled $S$. tanaceti genome resulted in identification of 204 (9.5\%) scaffolds containing acceptable repeat motifs. Of the 44 primers

TABLE 1. Isolates of Stagonosporopsis chrysanthemi and S. inoxydabilis used for cross-species transferability tests of the developed microsatellite markers

\begin{tabular}{|c|c|c|c|}
\hline Species & Accession no & Host & Country \\
\hline S. chrysanthemi & $\begin{array}{l}\text { ATCC } 10748 \\
\text { CBS 500.63; MUCL } 8090 \\
\text { DSMZ } 62547 \\
\text { DSMZ } 63133 \\
\text { ICMP } 10673 \\
\text { ICMP } 2287\end{array}$ & $\begin{array}{l}\text { Chrysanthemum morifolium } \\
\text { C. indicum } \\
\text { Chrysanthemum sp. } \\
\text { C. indicum } \\
\text { Chrysanthemum sp. } \\
\text { Chrysanthemum sp. }\end{array}$ & $\begin{array}{l}\text { USA } \\
\text { Germany } \\
\text { Germany } \\
\text { Germany } \\
\text { New Zealand } \\
\text { New Zealand }\end{array}$ \\
\hline S. inoxydabilis & $\begin{array}{l}\text { CBS } 425.90 ; \text { PD } 81 / 520 \\
\text { PD } 85 / 259 \\
\text { PD } 90 / 2040\end{array}$ & $\begin{array}{l}\text { C. parthenium } \\
\text { Matricaria } \mathrm{sp} . \\
\text { Matricaria } \mathrm{sp} .\end{array}$ & $\begin{array}{l}\text { Netherlands } \\
\text { Netherlands } \\
\text { Netherlands }\end{array}$ \\
\hline
\end{tabular}


tested, 41 (93\%), $12(27 \%)$, and 10 (22\%) successfully amplified a single band in $S$. tanaceti, $S$. inoxydabilis, and $S$. chrysanthemi, respectively. Sequencing of the PCR products confirmed the fragment identity with the scaffolds and presence of the SSR motifs.

Test for allelic variation and multiplex PCR optimization. Of the total of 41 SSR loci that were successfully amplified in $S$. tanaceti, 16 were polymorphic across the 24 isolates analyzed. Although primers that amplified in S. chrysanthemi were tested against only six isolates, three primer pairs were found to be polymorphic. None of the loci which amplified in S. inoxydabilis were polymorphic in the three isolates (Fig. 2). S. tanaceti did not share any alleles with $S$. chrysanthemi but had two alleles in common with $S$. inoxydabilis.

Genotyping. Three of the markers (St259, St868, and St1765) were found to have error rates of more than 0.04 and were eliminated from the analyses. Across the remaining 13 loci, the number of alleles ranged from 2 to 10 with an average of 2.9 alleles per locus. The Ewens-Watterson test did not find any deviations of allele distribution from neutral expectation (data not shown).

Geographical analysis of genetic diversity. In general, subpopulations had low to moderate gene diversity $\left(\mathrm{H}_{\mathrm{e}}=0.15\right.$ to
0.43). In 2012, gene diversity of two regions (Table Cape and East Devonport) was higher than the remainder, which may be a function of larger sample sizes. This is supported by the fact that allelic richness after rarefaction to the smallest population size was found to be similar between regions in 2012 (Table 2).

The measures of genotypic diversity in 2012 were similar across subpopulations with only one region (Howth) having a significantly lower genotypic diversity than the rest $(P=0.001)$. Similarly in 2013, subpopulations (defined by region, pyrethrum field, and variety) were found to have similar gene and genotypic diversity, only the genotypic diversity in field 49301 was significantly lower than the two other fields (Table 3).

Temporal analysis of genetic diversity. Low $\beta$ values in all years suggested the presence of a few large lineages and multiple small ones. Overall, gene diversity in different years ranged from 0.26 (in the pre-2004 collection) to 0.41 (in 2012) (Table 4). The chi-square tests found no significant difference in gene frequencies between the pre-2004 collection and the 2010 populations. However, there was a significant change in gene frequencies at nine loci between 2010 and 2012 (Fig. 3). Five of these loci showed a further change in gene frequencies between 2012 and 2013 (Supplemental Table 2).

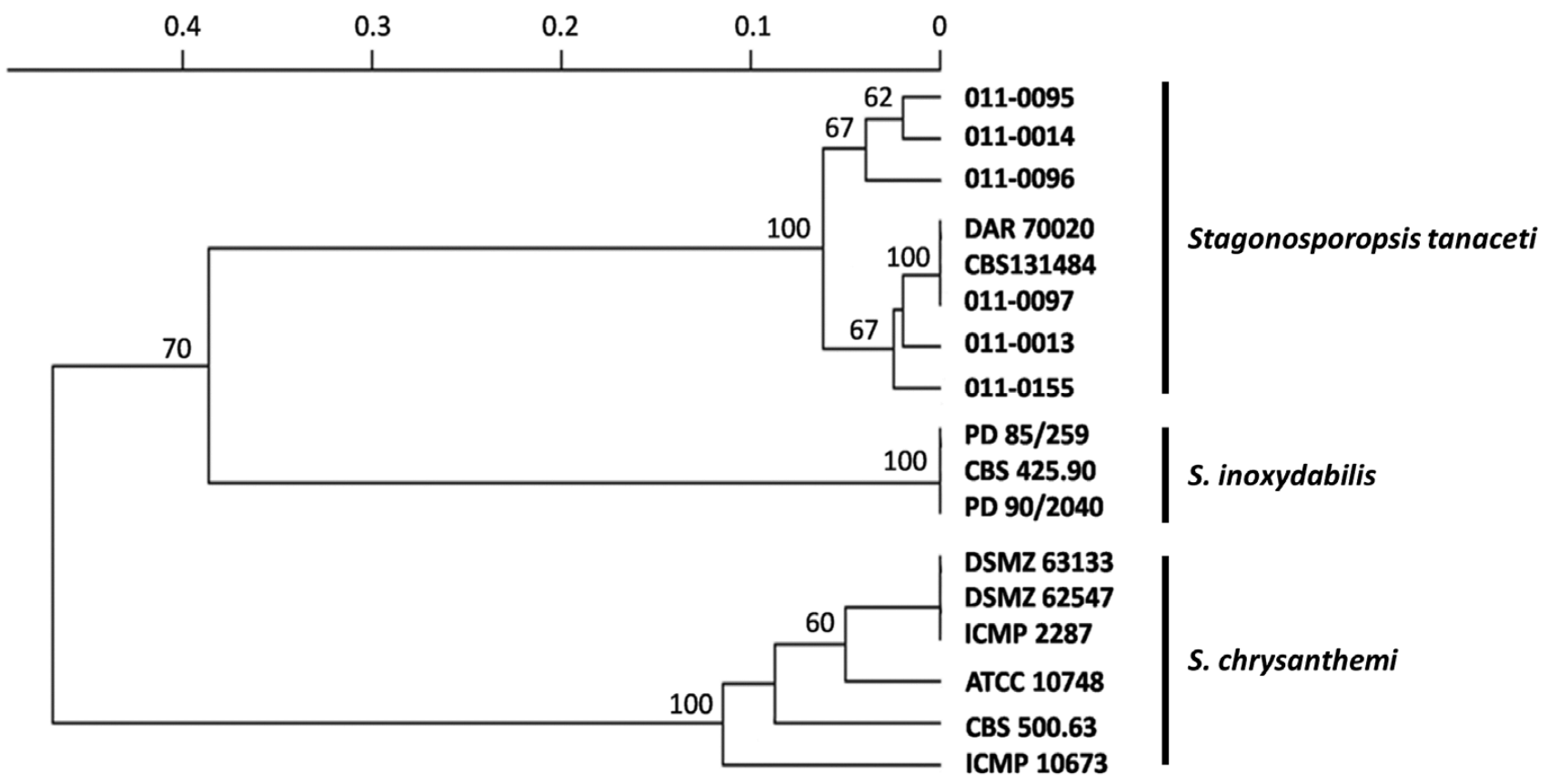

Fig. 2. Unweighted pair group method with arithmetic mean tree showing the relationship among Stagonosporopsis tanaceti, S. chrysanthemi, and S. inoxydabilis, based on Bruvo's distance (9) using the eight microsatellite markers that were transferable between the three species.

TABLE 2. Summary of genetic diversity indices for 2012 subpopulations of Stagonosporopsis tanaceti, defined by region and pyrethrum variety ${ }^{\mathrm{a}}$

\begin{tabular}{|c|c|c|c|c|c|c|c|c|c|c|c|}
\hline \multirow[b]{2}{*}{ Diversity Indices ${ }^{b}$} & \multicolumn{6}{|c|}{ Regions $^{c}$} & \multirow[b]{2}{*}{$\mathrm{F}_{\mathrm{ST}}$} & \multicolumn{3}{|c|}{ Varieties } & \multirow[b]{2}{*}{$\mathrm{F}_{\mathrm{ST}}$} \\
\hline & $\mathrm{TC}$ & $\mathrm{B}$ & $\mathrm{H}$ & WP & ED & WV & & Pyrate & Pyrite & RS5 & \\
\hline Sample size $(\mathrm{N})$ & 73 & 10 & 13 & 28 & 36 & 18 & $0.16(P=0.04)$ & 63 & 10 & 91 & $0.13(P<0.001)$ \\
\hline Allelic richness $\left(\mathrm{R}_{\mathrm{a}}\right)$ & 2.2 & 1.7 & 1.1 & 1.8 & 2.2 & 1.7 & & 2.1 & 1.7 & 2.1 & \\
\hline Number of private alleles $\left(\mathrm{P}_{\mathrm{a}}\right)$ & 0.17 & 0.02 & 0.05 & 0.14 & 0.07 & 0.02 & & 0.13 & 0.03 & 0.07 & \\
\hline Gene diversity $\left(\mathrm{H}_{\mathrm{e}}\right)$ & 0.43 & 0.18 & 0.15 & 0.25 & 0.40 & 0.18 & & 0.34 & 0.25 & 0.42 & \\
\hline Number of MLGs & 13 & 3 & 2 & 8 & 10 & 7 & & 13 & 3 & 18 & \\
\hline eMLG & 5.2 & 3 & 1.7 & 4.9 & 5.1 & 4.5 & & 4.7 & 3.0 & 5.3 & \\
\hline Genotypic richness (R) & 0.16 & 0.22 & 0.08 & 0.25 & 0.25 & 0.35 & & 0.19 & 0.22 & 0.17 & \\
\hline Evenness (ED) & 0.80 & 0.36 & 0.76 & 0.71 & 0.76 & 0.19 & & 0.66 & 0.36 & 0.75 & \\
\hline Genotypic diversity (D*) & 0.81 & 0.51 & $0.15^{*}$ & 0.77 & 0.81 & 0.63 & & 0.74 & $0.51 *$ & 0.79 & \\
\hline$\beta$ & 1.28 & n.c. & n.c. & 1.34 & 1.35 & 1.18 & & 1.21 & n.c. & 1.24 & \\
\hline
\end{tabular}

a Weir and Cockerham's (70) unbiased estimator of $\mathrm{F}_{\mathrm{ST}}$ was calculated using 10,000 randomizations.

${ }^{b} R_{a}=$ allelic richness after rarefaction to the smallest sample size, $\mathrm{P}_{\mathrm{a}}=$ number of private alleles after rarefaction, $\mathrm{H}_{\mathrm{e}}=$ Nei's index of gene diversity defined as the probability that two randomly chosen alleles are different, MLGs = multilocus genotype, eMLG = expected number of MLGs after rarefaction, $\mathrm{R}=$ genotypic richness, $\mathrm{R}=(\mathrm{G}-1) /(\mathrm{N}-1)$, and $\beta=$ the slope of Pareto distribution.

c $\mathrm{TC}=$ Table Cape, $\mathrm{B}=$ Burnie, $\mathrm{H}=$ Howth, $\mathrm{WP}=$ West Pine, $\mathrm{ED}=$ East Devonport, $\mathrm{WV}=$ Wesley Vale, and n.c. $=$ not calculated. 
All populations showed high genotypic diversity, and tests in GenoDive (31) found no significant difference between years $(P>$ $0.05)$, except for 2010 , which had a significantly higher genotypic diversity than other years $(P=0.006)$. In addition to the change in genotypic diversity, the genotypic composition in 2010 was significantly different from that in $2012(P=0.001)$. Although the genotypic diversity did not change between 2012 and 2013, there was also a significant change in genotypic composition of the two populations $(P=0.001)$. Hierarchical analysis of genetic variation within and among years found that $42 \%$ of the total genetic variation existed between years $(P=0.001)$, while only $9.5 \%$ of the variation was present among regions in each year $(P<0.001)$.

MLG analyses. In the total $407 \mathrm{~S}$. tanaceti isolates, 73 MLGs were found, indicating $82 \%$ clonality in the population. Of these, only 22 were isolated more than once, which, given the high clonality of the population, suggested the presence of a few dominant MLGs and multiple small lineages and singletons (MLGs that occur only once). This was confirmed by the low slope of the Pareto distribution for all populations (Table 4). Of the 22 MLGs isolated more than once, 16 crossed over years (Fig. 4). The probability of the recurrent MLGs having originated from distinct events of sexual reproduction was less than 0.05 for 20 MLGS (of a total of 22 recurrent MLGs) and all the more frequent MLGs had $P<0.001$, confirming the clonal origin of the repeated MLGs.

Population structure and differentiation. AMOVA analysis found no significant difference between the 1- and 3-year-old populations in 2010. There was low genetic differentiation between regions in 2012, and $16 \%$ the total genetic variation existed between regions $(P=0.04)$. Also, populations from different pyrethrum varieties (Pyrate, Pyrite, and RS5) showed low but significant level of differentiation $\left(\mathrm{F}_{\mathrm{ST}}=0.13, P<0.001\right)$. However, in 2013, $F_{\text {ST }}$ was very low and nonsignificant between regions, pyrethrum varieties (RS5 and RS7), or fields (Table 3).

The minimum spanning network revealed two distinct subnetworks in the pre-2004 collection (Bruvo distance $=0.19$ ), each consisting of one dominant MLG and multiple other MLGs at low frequencies (Fig. 5A). MLG32 was the most frequent MLG in one subnetwork, and MLG16 was the predominant MLG in the second. MLG32 and MLG16 differed by nine mutational steps at six loci. This concurred with results from UPGMA (Supplemental File 1) and DAPC analysis (Supplemental File 2), both of which found two clusters in the pre-2004 collection. MLG32 dominated the whole population (frequency $=0.48$ ) and was found in both the western and eastern regions (Supplemental Figure 1).

The same structure was found in 2010, where two subnetworks were apparent in the minimum spanning network (Fig. 5B), and two clusters in UPGMA and DAPC analyses. Similar to the pre2004 population, MLG32 and MLG16 were the most frequent MLGs in each subnetwork, with MLG32 being the most common in both western and eastern regions (frequency $=0.30$ ).

In 2012, there was a major change in the population composition with the appearance of a third subnetwork consisting of novel genotypes that were not detected in 2010 or the previous years (Fig. 5C). The first two subnetworks were still dominated by MLG32 and MLG16 genotypes. The third subnetwork consisted of seven novel genotypes and was dominated by MLG69 (different to MLG32 at a total of 10 loci, and to MLG16 at eight loci). Both UPGMA and DAPC analyses also included three clusters in the 2012 population. MLG32 remained the most fre-

TABLE 3. Summary of genetic diversity indices for 2013 subpopulations of Stagonosporopsis tanaceti, defined by region/pyrethrum variety and field ${ }^{\text {a }}$

\begin{tabular}{|c|c|c|c|c|c|c|c|}
\hline \multirow[b]{2}{*}{ Diversity indices $^{\mathrm{b}}$} & \multicolumn{2}{|c|}{ Regionc/variety } & \multirow[b]{2}{*}{$\mathrm{F}_{\mathrm{ST}}$} & \multicolumn{3}{|c|}{ Fields } & \multirow[b]{2}{*}{$\mathrm{F}_{\mathrm{ST}}$} \\
\hline & TC/RS5 & F/RS7 & & 70042 & 70047 & 49301 & \\
\hline Sample size (N) & 95 & 48 & $0.01(P=0.10)$ & 45 & 50 & 48 & $0.04(P=0.06)$ \\
\hline Allelic richness $\left(\mathrm{R}_{\mathrm{a}}\right)$ & 2.8 & 2.6 & & 2.7 & 2.5 & 2.6 & \\
\hline Number of private alleles $\left(\mathrm{P}_{\mathrm{a}}\right)$ & 0.52 & 0.16 & & 0.38 & 0.31 & 0.16 & \\
\hline Gene diversity $\left(\mathrm{H}_{\mathrm{e}}\right)$ & 0.37 & 0.30 & & 0.39 & 0.34 & 0.30 & \\
\hline Number of MLGs & 27 & 11 & & 13 & 17 & 11 & \\
\hline eMLG & 17 & 11 & & 13 & 15 & 11 & \\
\hline Genotypic richness (R) & 0.27 & 0.21 & & 0.27 & 0.32 & 0.21 & \\
\hline Evenness (ED) & 0.78 & 0.31 & & 0.63 & 0.71 & 0.31 & \\
\hline Genotypic diversity (D*) & 0.86 & 0.54 & & 0.76 & 0.83 & $0.54 *$ & \\
\hline$\beta$ & 1.31 & 1.11 & & 1.25 & 1.35 & 1.11 & \\
\hline
\end{tabular}

a Weir and Cockerham's (70) unbiased estimator of $\mathrm{F}_{\mathrm{ST}}$ was calculated using 10,000 randomizations.

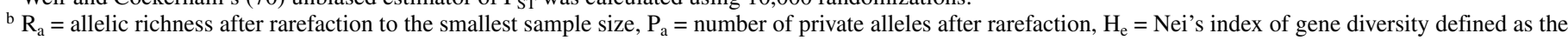
probability that two randomly chosen alleles are different, MLGs = multilocus genotype, eMLGs = expected number of MLGs after rarefaction, $\mathrm{R}=$ genotypic richness, $\mathrm{R}=(\mathrm{G}-1) /(\mathrm{N}-1)$, and $\beta=$ the slope of Pareto distribution.

${ }^{\mathrm{c}} \mathrm{TC}=$ Table Cape, $\mathrm{F}=$ Forthside.

TABLE 4. Summary of genetic diversity indices for Australian populations of Stagonosporopsis tanaceti collected in different years

\begin{tabular}{|c|c|c|c|c|}
\hline \multirow[b]{2}{*}{ Diversity indices $^{\mathrm{a}}$} & \multicolumn{4}{|c|}{ Population } \\
\hline & Pre-2004 collection & 2010 & 2012 & 2013 \\
\hline Sample size $(\mathrm{N})$ & 46 & 40 & 178 & 143 \\
\hline Number of alleles $\left(R_{a}\right)$ & 2.4 & 2.8 & 2.7 & 2.7 \\
\hline Number of private alleles $\left(\mathrm{P}_{\mathrm{a}}\right)$ & 0.2 & 0.7 & 0.3 & 0.5 \\
\hline Gene diversity $\left(\mathrm{H}_{\mathrm{e}}\right)$ & 0.26 & 0.27 & 0.41 & 0.35 \\
\hline Number of MLGs & 15 & 23 & 28 & 33 \\
\hline eMLG & 14 & 23 & 14 & 15 \\
\hline Clonal fraction & 0.67 & 0.43 & 0.84 & 0.77 \\
\hline Genotypic richness $(\mathrm{R})$ & 0.31 & 0.56 & 0.15 & 0.23 \\
\hline Evenness (ED) & 0.51 & 0.54 & 0.74 & 0.69 \\
\hline Genotypic diversity (D*) & 0.75 & $0.88 *$ & 0.79 & 0.79 \\
\hline c (Pareto) & 1.23 & 1.43 & 1.19 & 1.20 \\
\hline
\end{tabular}

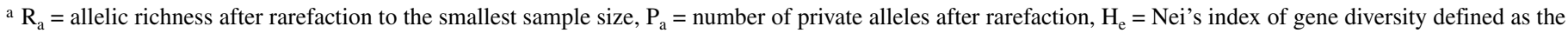
probability that two randomly chosen alleles are different, MLGs = multilocus genotype, eMLGs = expected number of MLGs after rarefaction, clonal fraction = $(\mathrm{N}-$ number of MLGs $) / \mathrm{N}, \mathrm{R}=$ genotypic richness, $\mathrm{R}=(\mathrm{G}-1) /(\mathrm{N}-1)$, and $\mathrm{c}$ Pareto $=\beta=$ the slope of Pareto distribution. 
quent genotype in the whole populations (frequency $=0.40$ ) followed by MLG16 (frequency $=0.15$ ) and the new MLG69 (frequency $=0.13$ ).

A similar structure to 2012 was found in 2013, with three subnetworks each consisting of one dominant MLG and multiple smaller genotypes (Fig. 5D). However, the number of genotypes increased from 7 to 16 between 2012 and 2013 in the third subnetwork. Also, MLG69 dominated the population (frequency = 0.41 ) followed by MLG3, the frequency of which increased from 0.07 in 2012 to 0.14 in 2013. On the other hand, the frequencies of the previously most common genotypes, MLG32 and MLG16, decreased to 0.10 and 0.06 , respectively.

The clusters detected in each year did not show a geographical pattern and were not associated with a specific pyrethrum variety or seed lot. The three clonal lineages occurred sympatrically in most pyrethrum fields and on all varieties tested (Pyrate, Pyrite, RS5, and RS7) and coexisted on individual plants (Fig. 6).

Linkage disequilibrium analyses. Both $\bar{r}_{d}$ and the ratio $\mathrm{Vo} / \mathrm{Ve}$ indicated significant levels of nonrandom association of alleles across all regions and years (Table 5).

\section{DISCUSSION}

This is the first study using microsatellite markers for population genetic analyses of $S$. tanaceti, the cause of ray blight of pyrethrum in Australia. Similar to previous studies $(10,27,62)$, partial de novo assembly of shotgun sequences was found to be a highly efficient method for microsatellite library development; with $93 \%$ success rate of PCR amplification. In contrast, microsatellite discovery in the unassembled shotgun reads using PALFINDER (11), although reported to have 30 to $90 \%$ amplification success in other studies $(34,35,37)$, gave a very low return for $S$. tanaceti (18\%).

Of the 44 primer pairs developed for the $S$. tanaceti genome, only 12 were transferrable to $S$. inoxydabilis. Also, 10 primer pairs amplified in $S$. chrysanthemi, three of which were polymorphic after screening against six isolates. Since conservation of the flanking sequences is not necessarily related to polymorphism of microsatellite loci $(4,21)$, higher polymorphism rates may be found for $S$. chrysanthemi and $S$. inoxydabilis when more individuals are genotyped.

Overall, $S$. tanaceti populations showed moderate gene diversity and higher than expected genotypic diversity, in agreement with an earlier study that used RAPD and AFLP markers (52). Discovery of high genotypic diversity in presumably asexual taxa, combined with linkage equilibrium of neutral loci and/or equal ratio of the opposite mating-type genes, has been taken as evidence of infrequent or cryptic sex $(7,13,17)$. However, identification of only one mating-type gene (MAT1-1-1) in $420 \mathrm{~S}$. tanaceti isolates (67) as well as the high level of clonality and significant linkage disequilibrium detected here and in a previous study (52), suggested the absence of a sexual cycle or any other process of recombination. Moreover, the high genotypic diversity was due to multiple singleton MLGs that differed mostly at only
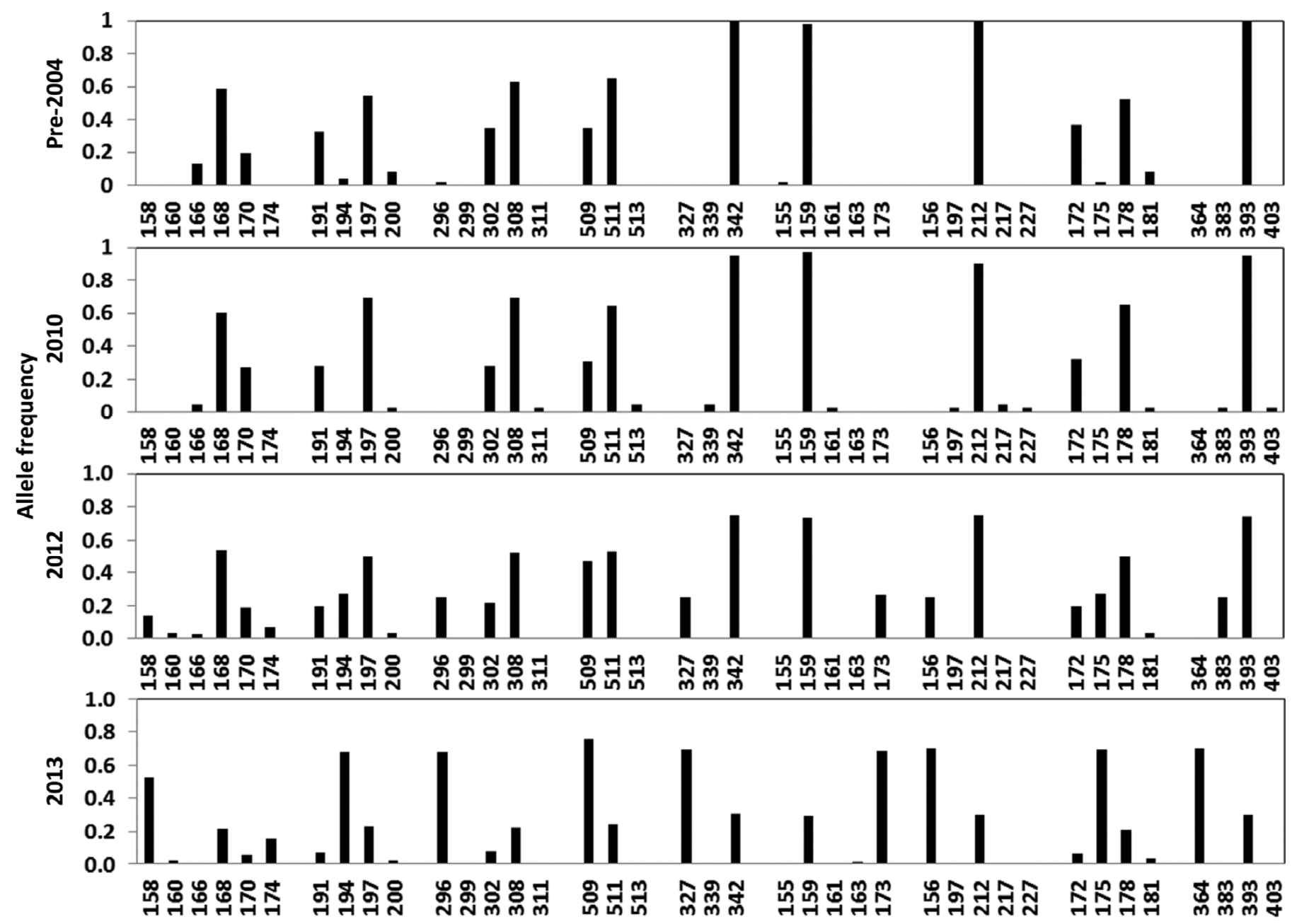

$\begin{array}{llllllllll}\text { Locus: } & \text { St986 } & \text { St11 } & \text { St2095 } & \text { St1681 } & \text { St1588 } & \text { St18 } & \text { St1407 } & \text { St11 } & \text { St1033 }\end{array}$

Fig. 3. Allele frequencies for the nine microsatellite loci that underwent a significant change in Stagonosporopsis tanaceti populations from 2010 to 2012. 
one or two loci. Such phenomenon may be due to high mutation rates or simply genotyping error.

A low but significant level of differentiation was detected between regions and pyrethrum varieties (Pyrate, Pyrite, and RS5) in 2012. The six regions in 2012 had been planted in 2011 with different varieties (RS5 in Table Cape and Wesley Vale; Pyrate in Howth, West Pine, and Devonport; and Pyrite in Burnie). Thus, the geographic differentiation detected in 2012 may be an artefact of the differentiation between pyrethrum varieties. In 2013, no significant differentiation was found among $S$. tanaceti populations defined on the basis of regions, fields, or pyrethrum varieties RS5 and RS7. These varieties are genetically close to each other and also believed to be less susceptible to ray blight than Pyrate and Pyrite (T. Groom, personal communication). This may be an indication of host specialization in the 2012 S. tanaceti population in response to the pyrethrum varieties, RS5 and RS7, which were introduced widely into commercial production in 2011.

The temporal analyses revealed genetic stability for over a decade, and then a rapid change in the genetic composition of $S$. tanaceti in only 2 years. The structure observed in the pre-2004 collection of $S$. tanaceti could still be observed in 2010, with two clusters of genotypes, each consisting of one dominant MLG (MLG32 or MLG16) and multiple closely related MLGs at low frequencies. No significant change in the allelic frequencies was detected between the two times.

In 2012, however, there was a significant change in allele frequencies at 9 of 13 loci as well as in overall genotypic composition. Multiple previously unobserved alleles and MLGs were detected in most regions in 2012. The novel MLGs constituted a third cluster of closely related clonal lineages with MLG69 being the dominant MLG. MLG32 and MLG16 remained most common genotypes in 2012, and widely distributed across different host varieties and regions. In 2013, another major change in the population composition was found as MLG32 and MLG16 were displaced with the novel MLGs (MLG69 and MLG3).

These results could be an artefact of insufficient sampling in and prior to 2010 as well as the ad hoc sampling strategies across fields in each year. However, the AMOVA showed that the proportion of the genetic variation between regions within each year was much lower than between years (only $9.5 \%$ of the variation existed between regions, while $42 \%$ of the variation existed between years). Moreover, the high frequency of the novel alleles and MLGs in 2012 and 2013 suggests a high probability of detection had they existed at the same frequency in previous years. Another key issue is the further increase in the frequency of newly detected MLGs in 2013 (MLG3 and MLG69), displacing the historically common MLGs (MLG32 and MLG16). Moreover, consistency of the population composition between the pre-2004 collection and the 2010 population indicated that the sampling strategy did not affect the detected population composition.

Rapid fluctuations of genetic composition in agroecosystems may occur simply due to genetic drift caused by local extinction and stochastic recolonization events. Such strong bottlenecks, however, are more likely in agricultural pathosystems with annual host species or perennial hosts with limited availability of the susceptible host tissue between seasons (e.g., deciduous perennials) (5). In contrast, on longer-lived hosts like pyrethrum, pathogen populations are likely to be more stable due to a higher rate of carry-over between seasons and maintenance of a larger effective population size $(56,66)$. In this study, the observed large changes in the population composition of $S$. tanaceti cannot be attributed to genetic drift.

The recent change in the $S$. tanaceti population could not be due to recombination or mutation. Our findings confirmed a clonal mode of reproduction for $S$. tanaceti, and also, the newly detected MLGs were not recombinant types but contained multiple previously unobserved alleles at 10 loci. The appearance of novel alleles could not be due to high mutation rates as it is unlikely that 1 to 11 mutational steps would occur at 10 loci simultaneously.

These findings may be explained by a second introduction of unique MLGs into pyrethrum growing areas. These MLGs may have been fitter (in terms of environmental tolerance, higher pathogenicity, or fungicide resistance) to enable replacement of common alleles and MLGs within the previous population.

An alternative explanation is that the newly detected MLGs may have existed in the population at very low frequency and

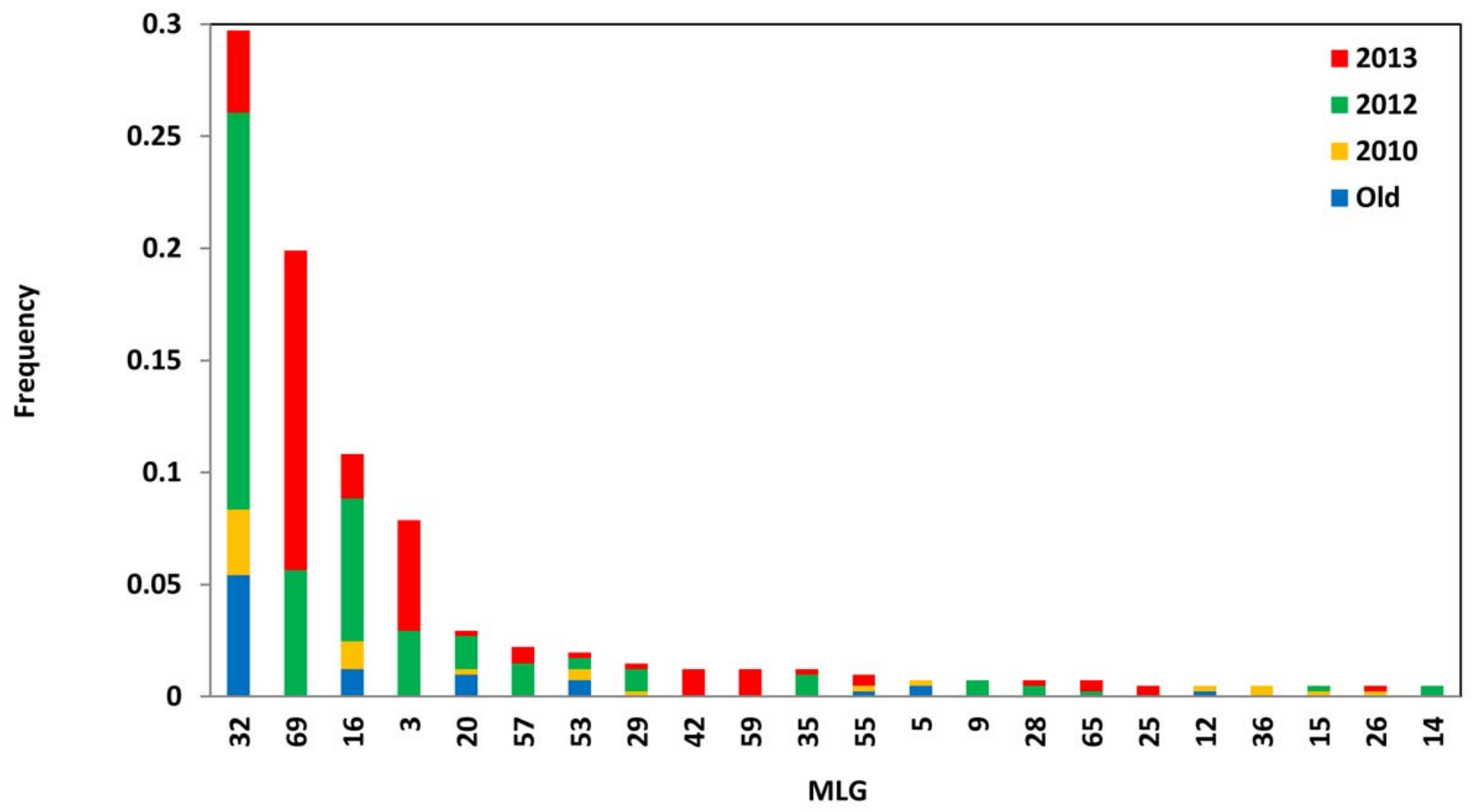

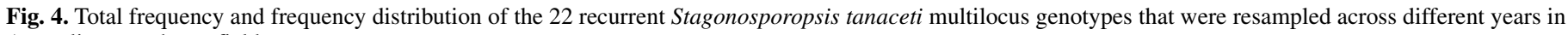
Australian pyrethrum fields. 
were hence undetected in the earlier collections. Their frequency may have increased due to a partial selective sweep $(32,33)$. Further increase in the frequency of the novel MLGs in 2013 which displaced MLG32 that had been the dominant MLG for over a decade reinforces the hypothesis that a selective sweep occurred.

Further investigation of these hypotheses is critical for successful disease management. Since the establishment of the industry, no further plant material has been imported into the breeding program, and also introduction of $S$. tanaceti through natural dispersal is highly unlikely especially in the absence of airborne ascospores (67). Therefore, the first hypothesis (a second introduction) implies existence of an endemic source of $S$. tanaceti. The detection of this source is critical to prevent subsequent introductions of new alleles and higher genetic diversity into the population.

Evidence for a selective sweep implies the presence of a strong selection pressure on the $S$. tanaceti population. Although microsatellite loci are selectively neutral, their ability to hitch-hike on ecologically important traits such as fungicide resistance or virulence genes, especially in strictly clonal species like $S$. tanaceti where the entire genome is effectively linked, has been suggested $(32,33)$. Rapid spread of one MLG in populations of Phytophthora infestans and displacement of other lineages in Great Britain in less than three years was associated with higher aggressiveness (12). The recent change in the $S$. tanaceti population coincides with the widespread use of multiple new fungicides, as well as large-scale planting of newer varieties. Wide- spread release of RS5 and RS7, which were believed to have anecdotally higher resistance to ray blight, could have selected for the newly detected MLGs. The association between the novel MLGs and changed phenological traits, such as aggressiveness and fungicide resistance, requires further assessment.

Testing whether the recent change in the $S$. tanaceti population was due to a second introduction then a selective sweep, or only a strong selection force, requires determining the original source of the pathogen. $S$. tanaceti could be a native Australian species on another member of the family Asteraceae, which jumped onto the imported pyrethrum and evolved into more virulent pathotypes through mutation followed by selective sweeps. Multiple studies have shown that introduction of a crop to a new area can result in new diseases due to pathogen host shifts. Such novel host-pathogen associations have been reported in multiple agroecosystems and some were proven to have occurred over a short time period $(14,39,61,72)$.

Although this is a valid hypothesis, a more likely scenario would be to assume an exotic origin for S. tanaceti. This is due to its close phylogenetic affinity to other ray blight pathogens of the family Asteraceae; S. chrysanthemi and S. inoxydabilis, which have been reported in the United States and Europe but not Australia $(67,68)$. Differentiation of the $S$. tanaceti population into two to three clonal lineages, each including one dominant genotype can be interpreted as a few independent introductions or introduction of a few MLGs and their subsequent divergence in the absence of admixture (6).
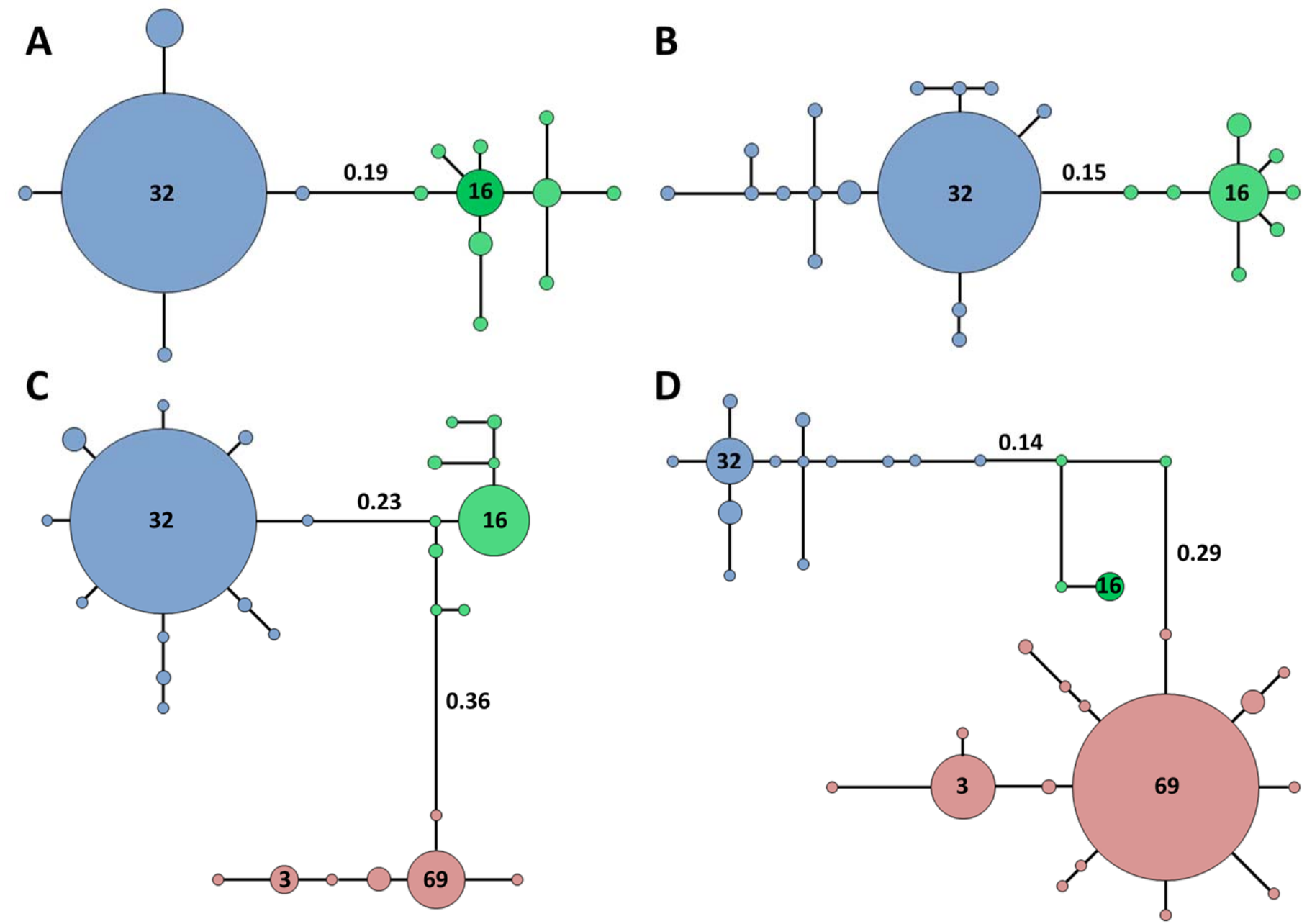

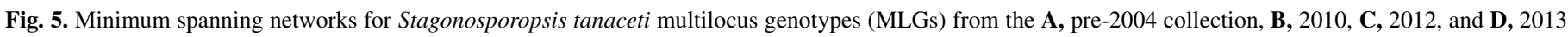

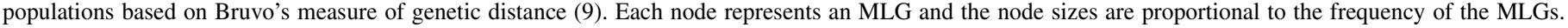

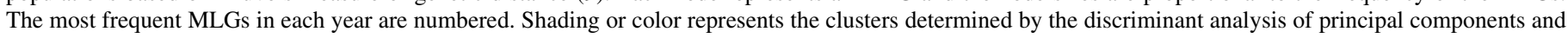

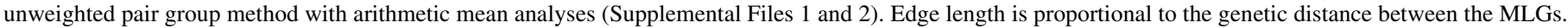


If an exotic source for $S$. tanaceti is assumed, the route of introduction into Australia remains unknown. One possible route may have been introduction on the propagative material imported from India. Initial introduction on the imported plants may have gone unnoticed due to the absence of symptoms as $S$. tanaceti is known to enter an endophytic stage in its life cycle (unpublished data). Reports of ray blight affecting chrysanthemum in Australia $(36,63)$ prior to the importation of pyrethrum could not be verified (68). Nevertheless, this suggests that $S$. tanaceti might have been around for several decades on other members of the family Asteraceae, and emerged in Tasmanian pyrethrum fields following a host shift. Although there is no information on $S$. tanaceti occurring naturally on other Asteraceae in Tasmania, Pethybridge et al. (45) found that it was able to infect a range of Asteraceae, including Tagetes patula and Chrysanthemum carinatum, in glasshouse trials.
In brief, the substantial change in the genetic composition of $S$. tanaceti population in just 2 years is most likely due to a second introduction then a selective sweep, or a strong selection pressure. Further studies are required to investigate whether the newly detected MLGs show higher aggressiveness or fungicide resistance. Inferring the origin of $S$. tanaceti would also help test these hypotheses, which emphasizes the importance of identifying alternative sources of $S$. tanaceti in Australia or elsewhere.

\section{ACKNOWLEDGMENTS}

We thank S. Pilkington and P. Weichelt, Tasmanian Institute of Agriculture, University of Tasmania, for technical support, and T. Groom, Botanical Resources Australia-Agricultural Services Pty. Ltd., for constructive discussions and agronomic information. This project was supported by Botanical Resources Australia-Agricultural Services Pty. Ltd.

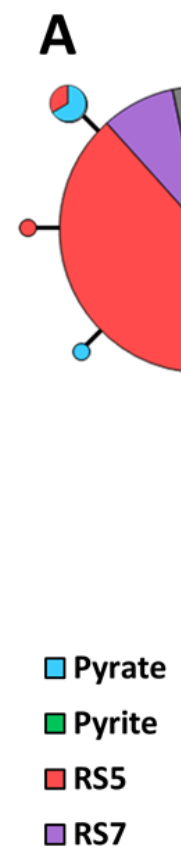

B

\section{口Unknown}

Fig. 6. Minimum spanning networks for Stagonosporopsis tanaceti multilocus genotypes (MLGs) from the A, 2012 and B, 2013 populations based on Bruvo's measure of genetic distance (9). Each node represents an MLG and the node sizes are proportional to the frequency of the MLGs. The most frequent MLGs in each year are numbered. Shading or color represents the pyrethrum varieties from which the samples were collected. Edge length is proportional to the genetic distance between the MLGs.

TABLE 5. Indices of linkage disequilibrium for each Stagonosporopsis tanaceti population defined by year, region, and field

\begin{tabular}{|c|c|c|c|c|c|c|}
\hline \multirow[b]{2}{*}{ Population $^{\mathrm{a}}$} & \multirow[b]{2}{*}{ Size } & \multirow[b]{2}{*}{ MLGs } & \multicolumn{2}{|c|}{$\overline{\boldsymbol{r}}_{\boldsymbol{d}}(P$ value $)$} & \multicolumn{2}{|c|}{$\mathrm{Vo} / \mathrm{Ve}(P(\mathrm{Vr}>=\mathrm{Vo}))$} \\
\hline & & & Not $c c^{b}$ & $\mathrm{cc}^{\mathrm{c}}$ & Not cc & $\mathrm{cc}$ \\
\hline Pre-2004 collection & 46 & 15 & $0.47(0.001)$ & $0.18(0.001)$ & $4.63(0.001)$ & $3.24(0.001)$ \\
\hline 2010 & 40 & 23 & $0.19(0.001)$ & $0.09(0.001)$ & $3.41(0.001)$ & $2.64(0.001)$ \\
\hline 2013 & 143 & 33 & $0.58(0.001)$ & $0.31(0.001)$ & $7.18(0.001)$ & $13.50(0.001)$ \\
\hline 2012_TC & 73 & 13 & $0.71(0.001)$ & $0.50(0.001)$ & $8.11(0.001)$ & $7.01(0.001)$ \\
\hline 2012_B & 10 & 3 & $0.67(0.001)$ & $0.18(0.144)$ & $6.34(0.001)$ & n.c. \\
\hline 2012_WV & 18 & 7 & $0.61(0.001)$ & $0.43(0.001)$ & $4.56(0.001)$ & $5.06(0.001)$ \\
\hline 2013_70047 & 45 & 13 & $0.66(0.001)$ & $0.40(0.001)$ & $7.60(0.001)$ & $6.20(0.001)$ \\
\hline 2013_70042 & 50 & 11 & $0.53(0.001)$ & $0.30(0.001)$ & $6.89(0.001)$ & $5.16(0.001)$ \\
\hline 2013_49301 & 48 & 17 & $0.66(0.001)$ & $0.35(0.001)$ & $8.07(0.001)$ & $6.13(0.001)$ \\
\hline
\end{tabular}

${ }^{\mathrm{a}} \mathrm{TC}=$ Table Cape, $\mathrm{B}=$ Burnie, $\mathrm{H}=$ Howth, $\mathrm{WP}=$ West Pine, ED = East Devonport, and WV = Wesley Vale.

${ }^{\mathrm{b}}$ Not $\mathrm{cc}=$ not clone-corrected data set.

${ }^{\mathrm{c}} \mathrm{cc}=$ clone-corrected data set.

d n.c. $=$ not calculated. 


\section{LITERATURE CITED}

1. Agapow, P. M., and Burt, A. 2001. Indices of multilocus linkage disequilibrium. Mol. Ecol. Notes 1:101-102.

2. Arnaud-Haond, S., and Belkhir, K. 2007. GENCLONE: A computer program to analyse genotypic data, test for clonality and describe spatial clonal organization. Mol. Ecol. Notes 7:15-17.

3. Arnaud-Haond, S., Duarte, C. M., Alberto, F., and Serrao, E. A. 2007. Standardizing methods to address clonality in population studies. Mol. Ecol. 16:5115-5139.

4. Arnold, C., Rossetto, M., McNally, J., and Henry, R. J. 2002. The application of SSRs characterized for grape (Vitis vinifera) to conservation studies in Vitaceae. Am. J. Bot. 89:22-28.

5. Barrett, L. G., Thrall, P. H., Burdon, J. J., and Linde, C. C. 2008. Life history determines genetic structure and evolutionary potential of hostparasite interactions. Trends Ecol. Evol. 23:678-685.

6. Berbegal, M., Pérez-Sierra, A., Armengol, J., and Grünwald, N. 2013. Evidence for multiple introductions and clonality in Spanish populations of Fusarium circinatum. Phytopathology 103:851-861.

7. Bihon, W., Slippers, B., Burgess, T., Wingfield, M. J., and Wingfield, B. D. 2012. Diverse sources of infection and cryptic recombination revealed in South African Diplodia pinea populations. Fungal Biol. 116:112-120.

8. Benson, G. 1999. Tandem repeats finder: A program to analyze DNA sequences. Nucleic Acids Res. 27:573-580.

9. Bruvo, R., Michiels, N. K., D’Souza, T. G., and Schulenburg, H. 2004. A simple method for the calculation of microsatellite genotype distances irrespective of ploidy level. Mol. Ecol. 13:2101-2106.

10. Cai, G., Leadbetter, C. W., Muehlbauer, M. F., Molnar, T. J., and Hillman, B. I. 2013. Genome-wide microsatellite identification in the fungus Anisogramma anomala using Illumina sequencing and genome assembly. PloS One 8:e82408.

11. Castoe, T. A., Streicher, J. W., Meik J. M., Ingrasci, M. J., Poole, A. W., Koning, A. P., Campbell, J. A., Parkinson, C. L., Smith, E. N., and Pollock, D. D. 2012. Thousands of microsatellite loci from the venomous coralsnake Micrurus fulvius and variability of select loci across populations and related species. Mol. Ecol. Res. 12:1105-1113.

12. Cooke, D. E., Cano, L. M., Raffaele, S., Bain, R. A., Cooke, L. R., Etherington, G. J., Deahl, K. L., Farrer, R. A., Gilroy, E. M., Goss, E. M., Grünwald, N. J., Hein, I., MacLean, D., McNicol, J. W., Randall, E., Oliva, R. F., Pel, M. A., Shaw, D. S., Squires, J. N., Tylor, M. C., Vleeshouwers, V. G. A. A., Birch, P. R. J., Lees, A. K., and Kamoun, S. 2012. Genome analyses of an aggressive and invasive lineage of the Irish potato famine pathogen. PLOS Pathog. 8:e1002940.

13. Cortinas, M. N., Barnes, I., Wingfield, B. D., and Wingfield, M. J. 2011. Unexpected genetic diversity revealed in the Eucalyptus canker pathogen Teratosphaeria gauchensis. Aust. Plant Pathol. 40:497-503.

14. Couch, B. C., Fudal, I., Lebrun, M. H., Tharreau, D., Valent, B., van Kim, P., Nottéghem, J. L., and Kohn, L. M. 2005. Origins of host-specific populations of the blast pathogen Magnaporthe oryzae in crop domestication with subsequent expansion of pandemic clones on rice and weeds of rice. Genetics 170:613-630.

15. Csardi, G., and Nepusz, T. 2006. The igraph software package for complex network research. InterJournal Complex Sys. 1695, No. 5.

16. Dorken, M. E., and Eckert, C. G. 2001. Severely reduced sexual reproduction in northern populations of a clonal plant, Decodon verticillatus (Lythraceae). J. Ecol. 89:339-350.

17. Duong, T. A., Beer, Z. W., Wingfield, B. D., Eckhardt, L. G., and Wingfield, M. J. Microsatellite and mating type markers reveal unexpected patterns of genetic diversity in the pine root-infecting fungus Grosmannia alacris. Plant Pathol. (In press)

18. Excoffier, L., Laval, G., and Schneider, S. 2005. Arlequin ver. 3.0: An integrated software package for population genetics data analysis. Evol. Bioinf. 1:47-50.

19. Holleley, C. E., and Geerts, P. G. 2009. Multiplex Manager 1.0: A crossplatform computer program that plans and optimizes multiplex PCR. BioTechniques 46:511-517.

20. Hurlbert, S. H. 1971. The nonconcept of species diversity: a critique and alternative parameters. Ecology 52:577-586.

21. Jan, C., Dawson, D. A., Altringham, J. D., Burke, T., and Butlin, R. K. 2012. Development of conserved microsatellite markers of high crossspecies utility in bat species (Vespertilionidae, Chiroptera, Mammalia). Mol. Ecol. Res. 12:532-548.

22. Jombart, T. 2008. Adegenet: A R package for the multivariate analysis of genetic markers. Bioinformatics 24:1403-1405.

23. Jombart, T., Devillard, S., and Balloux, F. 2010. Discriminant analysis of principal components: A new method for the analysis of genetically structured populations. BMC Genetics 11:94.

24. Jones, S. 2009. Characterisation of cultural, biological and molecular variability of Phoma ligulicola isolates associated with ray blight disease of pyrethrum and chrysanthemum. Ph.D. thesis, University of Tasmania,
Australia.

25. Jones, S., Pethybridge, S., Hay, F., Groom, T., and Wilson, C. 2007. Baseline sensitivity of Australian Phoma ligulicola isolates from pyrethrum to azoxystrobin and difenoconazole. J. Phytopathol. 155:377380 .

26. Kamvar, Z. N., Tabima, J. F., and Grünwald, N. J. 2014. Poppr: An R package for genetic analysis of populations with clonal, partially clonal, and/or sexual reproduction. PeerJ 2:e281.

27. Leo, A. E., Ford, R., Linde, C. C., Shah, R. M., Oliver, R., Taylor, P. W., and Lichtenzveig, J. 2011. Characterization of fifteen newly developed microsatellite loci for the chickpea fungal pathogen Ascochyta rabiei. Mol. Ecol. Res. 11:418-421.

28. Manly, B. F. J. 1985. The Statistics of Natural Selection on Animal Populations. Chapman and Hall, London, United Kingdom.

29. McDonald, B. A., and Linde, C. 2002. Pathogen population genetics, evolutionary potential and durable resistance. Annu. Rev. Phytopathol. 40:349-379.

30. McDonald, B. A., and Linde, C. 2002. The population genetics of plant pathogens and breeding strategies for durable resistance. Euphytica 124:163-180.

31. Meirmans, P. G., and Van Tienderen, P. H. 2004. GENOTYPE and GENODIVE: Two programs for the analysis of genetic diversity of asexual organisms. Mol. Ecol. Notes 4:792-794.

32. Milgroom, M. G., and Fry, W. E. 1997. Contributions of population genetics to plant disease epidemiology and management. Adv. Bot. Res. 24:1-30.

33. Milgroom, M. G., and Peever, T. L. 2003. Population biology of plant pathogens: The synthesis of plant disease epidemiology and population genetics. Plant Dis. 87:608-617.

34. Nunziata, S. O., Karron, J. D., Mitchell, R. J., Lance, S. L., Jones, K. L., and Trapnell, D. W. 2012. Characterization of 42 polymorphic microsatellite loci in Mimulus ringens (Phrymaceae) using Illumina sequencing. Am. J. Bot. 99:e477-e480.

35. O'Bryhim, J., Chong, J. P., Lance, S. L., Jones, K. L., and Roe, K. J. 2012. Development and characterization of sixteen microsatellite markers for the federally endangered species: Leptodea leptodon (Bivalvia: Unionidae) using paired-end Illumina shotgun sequencing. Cons. Gen. Res. 4:787-789.

36. Oxenham, B. L. 1963. Report of the Plant Pathology Section. Report for the Department of Agriculture, Queensland, Australia.

37. Oyler-McCance, S. J., Fike, J. A., Castoe, T. A., Tomback, D. F., Wunder, M. B., and Schaming, T. D. 2013. Development and characterization of thirteen microsatellite loci in Clark's nutcracker (Nucifraga columbiana). Cons. Gen. Res. 5:303-305.

38. Peakall, R. O. D., and Smouse, P. E. 2006. GENALEX 6: Genetic analysis in Excel. Population genetic software for teaching and research. Mol. Ecol. Notes 6:288-295.

39. Pérez, C., De Beer, Z., Altier, N., Wingfield, M., and Blanchette, R. 2008. Discovery of the eucalypt pathogen Quambalaria eucalypti infecting a non-Eucalyptus host in Uruguay. Aust. Plant Pathol. 37:600-604.

40. Pethybridge, S. J., Esker, P., Dixon, P., Hay, F. S., Groom, T., Wilson, C. R., and Nutter, F. W., Jr. 2007. Quantifying loss caused by ray blight disease in Tasmanian pyrethrum fields. Plant Dis. 91:1116-1121.

41. Pethybridge, S. J., Esker, P., Hay, F. S., Wilson, C. R., and Nutter, F. W. 2005. Spatiotemporal description of epidemics caused by Phoma ligulicola in Tasmanian pyrethrum fields. Phytopathology 95:648-658.

42. Pethybridge, S. J., Gent, D. H., Groom, T., and Hay, F. S. 2013. Minimizing crop damage through understanding relationships between pyrethrum phenology and ray blight disease severity. Plant Dis. 97:14311437.

43. Pethybridge, S. J., and Hay, F. 2001. Influence of Phoma ligulicola on yield, and site factors on disease development, in Tasmanian pyrethrum crops. Aust. Plant Pathol. 30:17-20.

44. Pethybridge, S. J., Hay, F., Jones, S., Wilson, C., and Groom, T. 2006. Seedborne infection of pyrethrum by Phoma ligulicola. Plant Dis. 90:891897.

45. Pethybridge, S. J., Hay, F. S., Clarkson, R., Groom, T., and Wilson, C. R. 2008. Host range of Australian Phoma ligulicola var. inoxydablis isolates from pyrethrum. J. Phytopathol.156:506-508.

46. Pethybridge, S. J., Hay, F. S., Esker, P., Groom, T., Wilson, C. R., and Nutter, F. W., Jr. 2008. Visual and radiometric assessments for yield losses caused by ray blight in pyrethrum. Crop Sci. 48:343-352.

47. Pethybridge, S. J., Hay, F. S., Esker, P. D., Gent, D. H., Wilson, C. R., Groom, T., and Nutter, F. W., Jr. 2008. Diseases of pyrethrum in Tasmania: Challenges and prospects for management. Plant Dis. 92:12601272.

48. Pethybridge, S. J., Hay, F. S., and Groom, T. 2003. Seasonal fluctuations in fungi associated with pyrethrum foliage in Tasmania. Aust. Plant Pathol. 32:223-230.

49. Pethybridge, S. J., Hay, F. S., Groom, T., and Wilson, C. R. 2008. 
Improving fungicide-based management of ray blight disease in Tasmanian pyrethrum fields. Plant Dis. 92:887-895.

50. Pethybridge, S. J., Hay, F. S., Wilson, C. R., and Groom, T. 2005. Development of a fungicide-based management strategy for foliar disease caused by Phoma ligulicola in Tasmanian pyrethrum fields. Plant Dis. 89:1114-1120.

51. Pethybridge, S. J., Ngugi, H., and Hay, F. S. 2010. Use of survival analysis to assess management options for ray blight in Australian pyrethrum fields. Plant Pathol. 59:480-491.

52. Pethybridge, S. J., Scott, J. B., and Hay, F. S. 2012. Lack of evidence for recombination or spatial structure in Phoma ligulicola var. inoxydabilis populations from Australian pyrethrum fields. Plant Dis. 96:746-751.

53. Pethybridge, S. J., and Wilson, C. R. 1998. Confirmation of ray blight disease of pyrethrum in Australia. Aust. Plant Pathol. 27:45-48.

54. Pompanon, F., Bonin, A., Bellemain, E., and Taberlet, P. 2005. Genotyping errors: Causes, consequences and solutions. Nature Rev. Gen. 6:847-846.

55. Pritchard, J. K., Stephens, P., and Donnelly, P. 2000. Inference of population structure using multilocus genotype data. Genetics 155:945-959.

56. Prospero, S., and Rigling, D. 2012. Invasion genetics of the chestnut blight fungus Cryphonectria parasitica in Switzerland. Phytopathology 102:73-82.

57. R Core Team. 2013. R: A language and Environment for Statistical Computing. R Foundation for Statistical Computing. Vienna, Austria. http://www.R-project.org/

58. Rozen, S., and Skaletsky, H. 2000. Primer3 on the WWW for general users and for biologist programmers. Pages 365-386 in: Bioinformatics Methods and Protocols: Methods in Molecular Biology. S. Krawetz and S. Misener, eds. Humana Press, Totowa, NJ.

59. Schliep, K. P. 2011. Phangorn: Phylogenetic analysis in R. Bioinformatics 27:592-593.

60. Schuelke, M. 2000. An economic method for the fluorescent labeling of PCR fragments. Nat. Biotechnol. 18:233-234.

61. Silva, D. N., Talhinhas, P., Cai, L., Manuel, L., Gichuru, E. K., Loureiro, A., Várzea, V., Paulo, O. S., and Batista, D. 2012. Host jump drives rapid and recent ecological speciation of the emergent fungal pathogen Colletotrichum kahawae. Mol. Ecol. 21:2655-2670.

62. Silva, P. I., Martins, A. M., Gouvea, E. G., Pessoa-Filho, M., and Ferreira, M. E. 2013. Development and validation of microsatellite markers for Brachiaria ruziziensis obtained by partial genome assembly of Illumina single-end reads. BMC Genomics 14:17.

63. Simmonds, J. H. 1996. Host index of plant disease in Queensland. Queensland Department of Primary Industries, Brisbane.

64. Stevens, F. L. 1907. The chrysanthemum ray blight. Bot. Gaz. 44:241258.

65. Szpiech, Z. A., Jakobsson, M., and Rosenberg, N. A. 2008. ADZE: A rarefaction approach for counting alleles private to combinations of populations. Bioinformatics 24:2498-2504.

66. Thrall, P. H., Biere, A., and Antonovics, J. 1993. Plant life-history and disease susceptibility. The occurrence of Ustilago violacea on different species within the Caryophyllaceae. J. Ecol. 81:489-498.

67. Vaghefi, N., Ades, P. K., Hay, F. S., Pethybridge, S. J., Ford, R., and Taylor, P. W. J. Identification of the MAT1 locus in Stagonosporopsis tanaceti, and exploring its potential for sexual reproduction in Australian pyrethrum fields. Fung. Biol. (In press)

68. Vaghefi, N., Pethybridge, S. J., Ford, R., Nicolas, M. E., Crous, P. W., Taylor, P. W. J. 2012. Stagonosporopsis spp. associated with ray blight disease of Asteraceae. Aust. Plant Pathol. 41:675-686.

69. Van der Aa, H., Noordeloos, M., and De Gruyter, J. 1990. Species concepts in some larger genera of the Coelomycetes. Stud. Mycol. 32:319.

70. Weir, B. S., and Cockerham, C. C. 1984. Estimating F-statistics for the analysis of population structure. Evolution 38:1358-1370.

71. Yeh, F. C., Yang, R. C., Boyle, T. B., Ye, Z. H., and Mao, J. X. 1997. POPGENE, the user-friendly shareware for population genetic analysis. Molecular Biology and Biotechnology Centre, University of Alberta, Canada.

72. Zaffarano, P. L., McDonald, B. A., and Linde, C. 2008. Rapid speciation following recent host shifts in the plant pathogenic fungus Rhynchosporium. Evolution 62:1418-1436. 